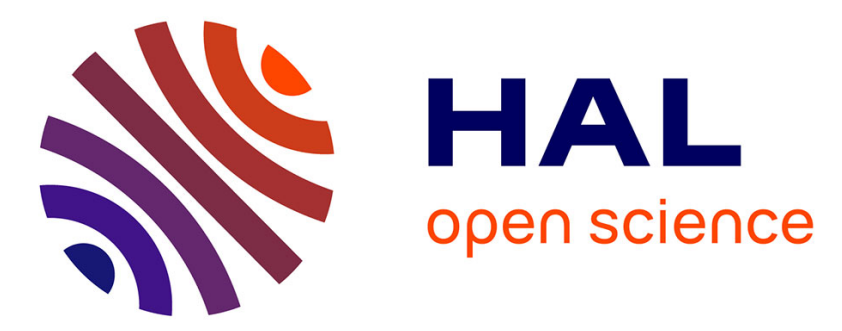

\title{
Series arcing detection by algebraic derivative of the current
}

\author{
Etienne Tisserand, Jinmi Lezama, Patrick Schweitzer, Yves Berviller
}

\section{To cite this version:}

Etienne Tisserand, Jinmi Lezama, Patrick Schweitzer, Yves Berviller. Series arcing detection by algebraic derivative of the current. Electric Power Systems Research, 2015, 119, pp.91 - 99. 10.1016/j.epsr.2014.09.011. hal-01397359

\section{HAL Id: hal-01397359 \\ https://hal.univ-lorraine.fr/hal-01397359}

Submitted on 26 Mar 2019

HAL is a multi-disciplinary open access archive for the deposit and dissemination of scientific research documents, whether they are published or not. The documents may come from teaching and research institutions in France or abroad, or from public or private research centers.
L'archive ouverte pluridisciplinaire HAL, est destinée au dépôt et à la diffusion de documents scientifiques de niveau recherche, publiés ou non, émanant des établissements d'enseignement et de recherche français ou étrangers, des laboratoires publics ou privés. 


\title{
E. TISSERAND - J. LEZAMA - P. SCHWEITZER - Y. BERVILLER
}

\section{Series arcing detection by algebraic derivative of the current}

\begin{abstract}
We present in this paper an algebraic derivative method of the line current in order to detect the presence of series arcs in an AC or DC electrical installation. The first derivative is computed from a limited Taylor-McLaurin series transposed in Laplace space. The temporal estimation is achieved by integration over a sliding window of the product of a particular polynomial with the instantaneous current. The discrete version can be synthesized by a simple FIR filter.

The tests, with and without series arc, are conducted on experimental currents (3-12 A) measured on domestic loads (resistors, vacuum drill, dimmer). The sampling frequency is set to $1 \mathrm{MHz}$.

Short integration times (50 microseconds in AC and 200 microseconds in DC) are sufficient to observe, with high contrast, the derivative peaks due to the arc ignition. The detection is then performed by comparing the derivation filter output to its instantaneous noise level. The response time is equal to the integration duration.

This method, simple to set up and easy to implement, is ideally suited for installations that do not use load switching current.
\end{abstract}

\section{I - Context and objectives}

Arc-fault detection, especially series arcing, is a key factor for increasing the safety of DC and AC power supply systems [1-2].

A series arc occurs in a galvanic interruption of the supply circuit. Involuntary separation of a contact point (breaking or disconnection) or insulation breakdown by carbon path, are the main causes of series arcs [3]. Less frequently, the arc can be initiated by a power overvoltage.

Physically it is reflected in a current flow across the discontinuity. This results strong local temperature increase which causes the ionization of the air in the form of plasma. Since the current intensity is limited by the load, the average level takes no abnormal value which makes the series arcs detection very difficult and gives them a high hazard potential.

In the presence of a series arc, the temporal shape of the current reveals :

- disruptions in the average level in DC mode. The resistance of the arc being often low, the current slightly decreases.

- discontinuities in the sinusoidal shape in AC mode.

Spectrum analysis is the most often used detection method [4-6]. The frequency range is selected to avoid interferences caused by the load.

Statistical analysis has proven advantages in some situations [7]. In the DC mode, the rupture detection can be achieved through the Page-Hinkley procedure which requires the selection of detection thresholds based on the noise level [8]. In the case of chaotic signals, multiple false detections can appear.

The time-frequency or time-scale decomposition can provide the frequency characteristics of the arc during its evolution [9-12].

Some authors propose detection based on the estimation of the impedance of the arc [13]. This method is more sensitive than the simple spectrum analysis, but requires knowledge about the arc voltage which is not actually possible in practical situations.

Other methods rely on identifying a real-time model of the load [14-17]. An arc can be considered a non-linear and chaotic variable dipole; its apparition leads to a strong prediction error in the model. The proposed solutions are often restricted to special cases (single power system, known load, range of spectrum analysis tailored to the situation, unique ignition mode). 
We propose in this work a detection technique based primarily on the time derivative of the line current. We searched for a derivative estimator which has high robustness to noise present in the signal [18-20]. Indeed, in real situations, especially in dwellings or in an industrial environment, the current can be polluted by a multitude of internal and external sources (LF induction, Power Line Communications, EMI ...). Also for practical reasons the current measurement is generally carried out using Hall effect probes whose accuracy and noise immunity are far from excellent.

This detection method which is suitable for situations that involve different types of load is usable in DC or AC system. It is compatible with arcs ignited by contact opening or by carbon path.

The method is suitable for low or high values of current. As the series arc detection is generally more difficult for low currents, all tests of this paper are made with domestic loads whose power is less than $2000 \mathrm{~W}$.

\section{II - Equipment and Method}

\section{1) Test-bench}

The test bench developed specifically for this study is shown schematically in Figure 1 [21]. It has a mixed $4 \mathrm{~kW}$ power supply (270 V DC and $220 \mathrm{~V} \mathrm{AC}, 50 \mathrm{~Hz}$ ) which supplies different charges $\mathrm{Z}$. In our tests we used resistive loads, appliances with universal motors and current switching systems (dimmer).

An arc triggering device (CPT/COT) is inserted in series with the load. The current I is measured by a Hall effect probe. It is sampled at frequency $\mathrm{f}_{\mathrm{s}}$ of $1 \mathrm{MHz}$ and recorded using a Lecroy WavePro 950 digital storage oscilloscope

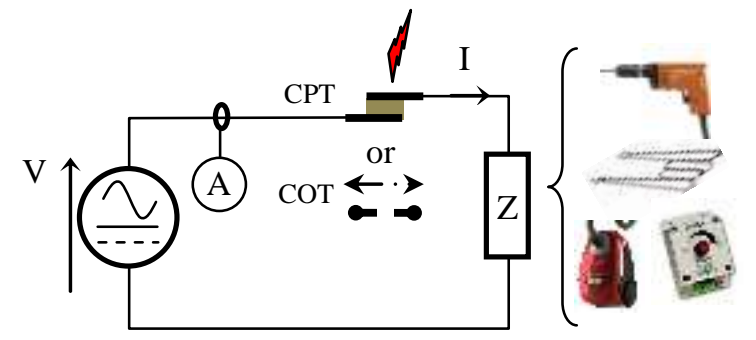

Figure 1. Diagram of the experimental setup

All calculations are done using Matlab. All algorithms are implemented in Simulink.

\section{2) Arc ignition methods}

Several kinds of arc tests are available [22-23]. We use the carbonized path (CPT) and the contact opening test (COT) according to the UL1699 standard. [24]

\section{Carbonized path test (CPT)}

The carbonized path test is based on two electric wires that have an insulation fault (Figure 2). We damage the insulation with a knife (cut about $0.5 \mathrm{~cm}$ long). The carbonization process involves complex chemical reactions. It starts with the heat rise; sparks and fire can appear.

\section{Contact opening test (COT)}

The usual interpretation of the arcing during contact opening involves two main phases. Upon detachment of the contact, the reduction in the conducting area introduces a localized resistive point which heats quickly. The thermal effect in turn leads to a molten metal bridge. When the conducting bridge breaks, it gives rise to plasma consisting of ions from the metal and the surrounding medium (initially an insulator). The conduction in this ionized medium takes the form of an electric arc. 
In our setup, one tungsten electrode and one cooper electrode are in touch while a nominal current goes through the circuit. A robotic cylinder (Figure 3) makes a separation between the electrodes ( $0.03 \mathrm{~mm}$ resolution).

This test reproduces what can happen in a relay, in a breaker or during an unexpected unplugging. In order to choose a gap value we conducted preliminary tests for different values of the gap. With a value of $0.1 \mathrm{~mm}$, the holding voltage of the arc is around $10 \mathrm{~V}$ and the current drop is very low. Most often one can observe an intermediate glow phenomenon between the molten bridge and the true arc. For values greater than $1.1 \mathrm{~mm}$, the arc is obtained in most cases and its voltage exceeds 30 $\mathrm{V}$. The COT presented here was obtained with a reference gap of $1.1 \mathrm{~mm}$ and an opening speed of $10 \mathrm{~mm} / \mathrm{s}$.

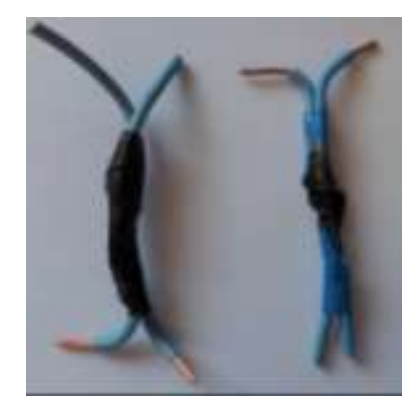

Figure 2. Carbonized Path

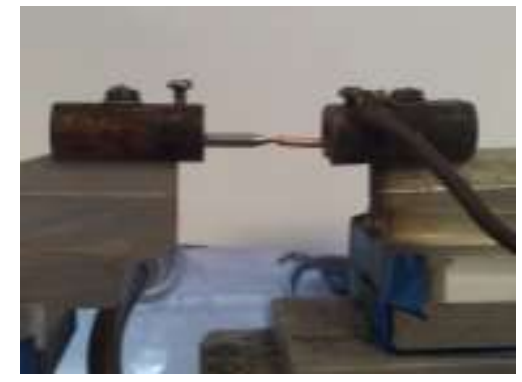

Figure 3. Robotic cylinder

\section{3) Experimental conditions}

Experimental conditions and the specifications of the loads used are summarized in Table 1.

\begin{tabular}{|c|c|c|c|c|}
\hline & V & Arc ignition & Load & I $_{\text {RMS }}$ \\
\hline Test 1 & DC & COT & $\mathrm{R}=34 \Omega$ & $8 \mathrm{~A}$ \\
\hline Test 2 & AC & CPT & $\mathrm{R}=48 \Omega$ & $4.8 \mathrm{~A}$ \\
\hline Test 3 & AC & CPT & Motor & $5.5 \mathrm{~A}$ \\
\hline Test 4 & AC & CPT & Several & Variable \\
\hline
\end{tabular}

For all tests : Pressure $=1$ Atm., Temperature $=22{ }^{\circ} \mathrm{C}$, Sampling frequency $: 1 \mathrm{MHz}$

Table 1. Expérimental conditions

For the DC mode we used the COT to properly control the time of occurrence of the arc, the only reliable indicator of the presence of a DC arc.

For the AC case we realize only the CPT that is the only ones recommended by the IEC62606 European standard.

\section{4) Typical currents}

The waveforms of currents recorded during these tests are shown in Figures 4 to 9. With the range used here, the measurement resolution (noise of the Hall effect probe and the quantization) is about $0.25 \mathrm{~A}$. The noise level is almost doubled in the test involving the universal motor. Indeed this generates micro arcs between the collector and the brushes during the rotation of the motor. 


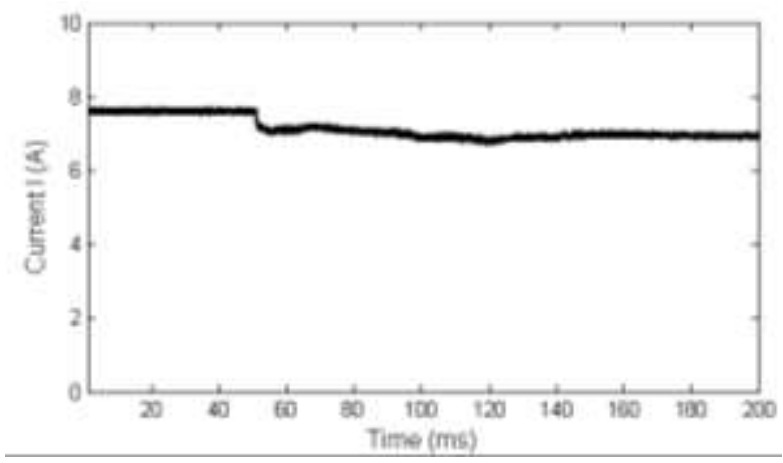

Figure 4. DC current during test 1

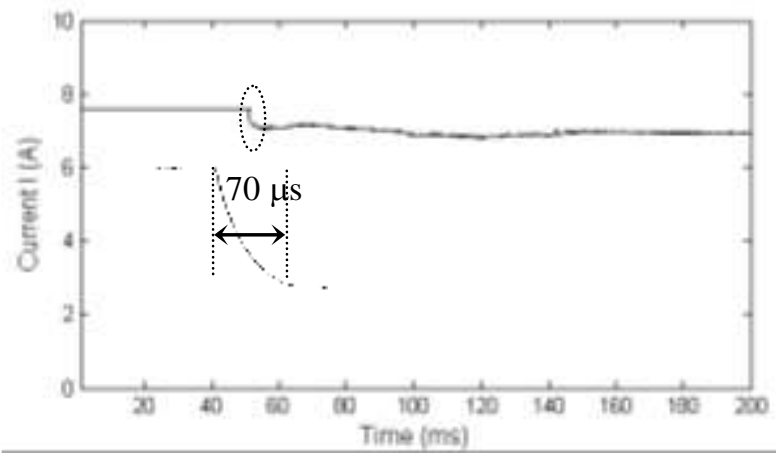

Figure 5. DC current after a $4 \mathrm{kHz}$ LP filtering - Zoom on the ignition phase

In the ignition phase of the arc (see zoom in Figure 5) the time constant is on the order of 70 microseconds. It corresponds to a rate of change of the current of about $8 \mathrm{kA} / \mathrm{s}$.

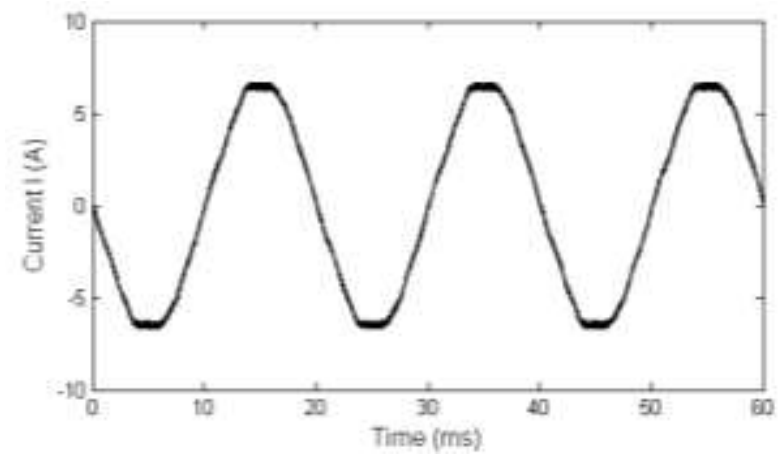

Figure 6. AC current in a resistive load without an arc

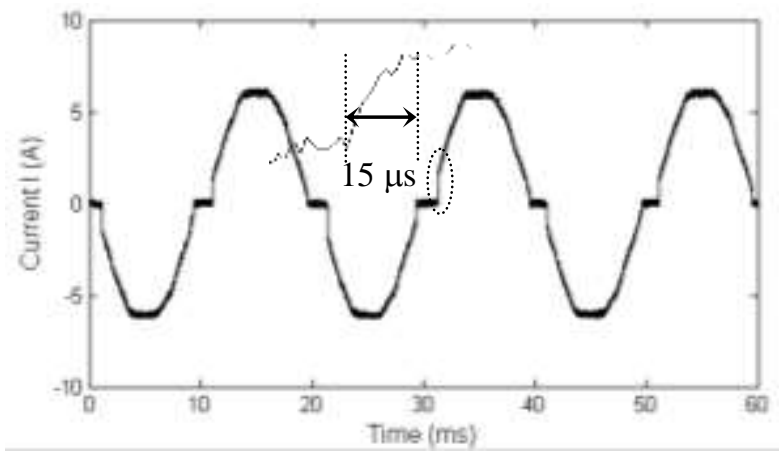

Figure 7 AC current in a resistive load with a series arc - Zoom on the ignition phase 


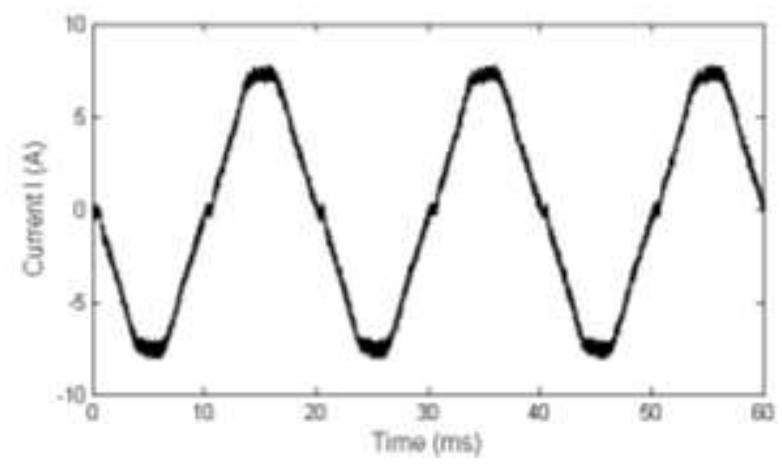

Figure 8. AC current in a universal motor without an arc

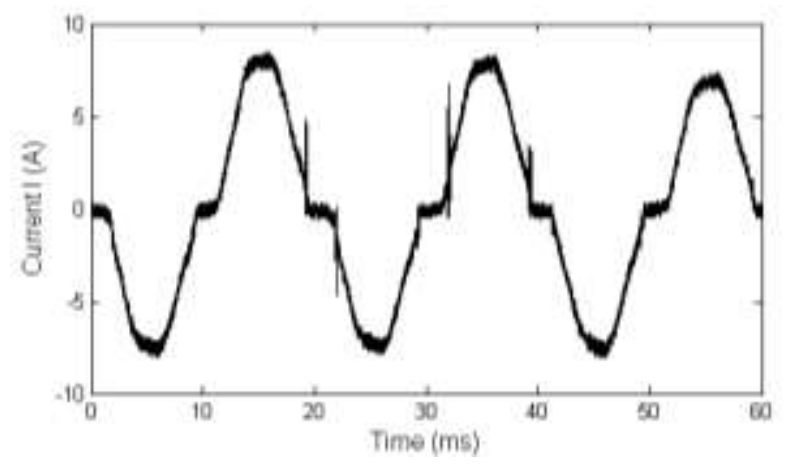

Figure 9. AC current in a universal motor with a series arc

On AC systems, an arc occurs when the arc voltage reaches the restrike value. Then one can note a sudden change lasting about $15 \mu \mathrm{s}$ (see zoom in Figure 7) after each zero crossing of the current. This corresponds to a rate of change of current of $110 \mathrm{kA} / \mathrm{s}$. This duration is shorter than for DC systems because it involves successive restrikes which by nature are faster than the initial ignition.

\section{III - Algebraic derivative}

\section{1) Preamble}

The estimate of the derivative of a noisy digital signal can be performed in different ways which can be grouped into three broad categories.

- The first is the traditional finite difference method.

- The estimate can also be obtained by deriving an analytical function previously fitted on each segment of the signal.

- Finally it is possible to use an algebraic estimator.

Finite difference methods have the advantage of being quick and simple to implement. However, they have inherently high sensitivity to noise and in practice require a previously low-pass filtered signal. Their use is only possible if the frequency characteristics of the noise are known and stationary. The best derivative/noise ratio results from a tedious compromise between the order of the finite difference, the sampling period and the cutoff frequency of the filter.

The second approach is more robust with respect to noise but requires the choice of a suitable model function (polynomial, exponential ...). The fitting is usually performed according to the least squares criterion. The presence of discontinuities in the signal can lead to high estimation errors when the $\mathrm{X}^{\mathrm{T}} \mathrm{X}$ matrix is close to singularity.

The estimate of the algebraic derivation is very recent. It was first proposed by Fliess and Join in 2004 and expanded in 2009 [20]. She has since confirmed its excellent performance on noisy measurement signals [25-29]. Its operations in the context of arc faults detection has, to the best of our knowledge, not yet been attempted before this paper. 


\section{2) Theoretical background}

Consider a real function $\mathrm{f}(\mathrm{t})$. Its Taylor-McLaurin series development is written :

$\mathrm{f}(\mathrm{t})=\mathrm{f}(0)+\frac{\mathrm{f}^{\prime}(0)}{1 !} \mathrm{t}+\frac{\mathrm{f}^{\prime \prime}(0)}{2 !} \mathrm{t}^{2}+\cdots+\frac{\mathrm{f}^{(\mathrm{n})}(0)}{\mathrm{n} !} \mathrm{t}^{\mathrm{n}}+\cdots$

It corresponds to a polynomial of the form : $\mathrm{f}(\mathrm{t})=\mathrm{a}_{0}+\frac{\mathrm{a}_{1}}{1 !} \mathrm{t}+\frac{\mathrm{a}_{2}}{2 !} \mathrm{t}^{2}+\cdots+\frac{\mathrm{a}_{\mathrm{n}}}{\mathrm{n} !} \mathrm{t}^{\mathrm{n}}+\cdots$

In which the $a_{j}$ coefficient is an estimate of the $j^{\text {th }}$ derivative of the signal for $t=0$

The limitation of the previous development to the $n^{\text {th }}$ degree is equivalent to consider that $\frac{\mathrm{d}^{\mathrm{n}+1} \mathrm{f}(\mathrm{t})}{\mathrm{dt}^{\mathrm{n}+1}}=0$

The Laplace transform of the function $\frac{\mathrm{d}^{\mathrm{n}+1} \mathrm{f}(\mathrm{t})}{\mathrm{dt}^{\mathrm{n}+1}}$ can be written as :

$L\left\{\frac{d^{n+1} f(t)}{d t^{n+1}}\right\}=p^{n+1} F(p)-p^{n} f(0)-p^{n-1} \frac{d f(0)}{d t}-\cdots-\frac{d^{n} f(0)}{d t^{n}}=0$

This leads to :

$\mathrm{p}^{\mathrm{n}+1} \mathrm{~F}(\mathrm{p})=\mathrm{p}^{\mathrm{n}} \mathrm{f}(0)+\mathrm{p}^{\mathrm{n}-1} \frac{\mathrm{df}(0)}{\mathrm{dt}}+\cdots+\frac{\mathrm{d}^{\mathrm{n}} \mathrm{f}(0)}{\mathrm{dt}^{\mathrm{n}}}=\mathrm{p}^{\mathrm{n}} \mathrm{a}_{0}+\mathrm{p}^{\mathrm{n}-1} \mathrm{a}_{1}+\cdots+\mathrm{a}_{\mathrm{n}}$

To isolate $\mathrm{a}_{1}$, the first derivative that interests us, one should make successive derivatives with respect to $\mathrm{p}$ in expression (2).

To simplify the presentation of the procedure, we limit the development at $\mathrm{n}=2$

$\mathrm{p}^{3} \mathrm{~F}(\mathrm{p})=\mathrm{p}^{2} \mathrm{a}_{0}+\mathrm{pa}_{1}+\mathrm{a}_{2}$

A first derivative eliminates the coefficient $\mathrm{a}_{2}$ :

$\frac{\left.\mathrm{d} \mid \mathrm{p}^{3} \mathrm{~F}(\mathrm{p})\right]}{\mathrm{dp}}=3 \mathrm{p}^{2} \mathrm{~F}(\mathrm{p})+\mathrm{p}^{3} \frac{\mathrm{d}[\mathrm{F}(\mathrm{p})]}{\mathrm{dp}}=2 \mathrm{a}_{0} \mathrm{p}+\mathrm{a}_{1}$

Dividing by $\mathrm{p}$ we obtain :

$3 \mathrm{pF}(\mathrm{p})+\mathrm{p}^{2} \frac{\mathrm{d}[\mathrm{F}(\mathrm{p})]}{\mathrm{dp}}=2 \mathrm{a}_{0}+\frac{\mathrm{a}_{1}}{\mathrm{p}}$

The derivative of the former expression allows us to isolate the coefficient $\mathrm{a}_{1}$ :

$3 F(p)+5 p \frac{d[F(p)]}{d p}+p^{2} \frac{d^{2}[F(p)]}{d p^{2}}=-\frac{a_{1}}{p^{2}}$

The $\mathrm{p}$ operators (time derivative is very sensitive to noise) should be suppressed in favor of $\frac{1}{\mathrm{p}}$ operators (temporal integration is more robust in the presence of noise).

To do this we divide by $\mathrm{p}^{3}$ giving :

$3 \frac{\mathrm{F}(\mathrm{p})}{\mathrm{p}^{3}}+\frac{5}{\mathrm{p}^{2}} \frac{\mathrm{d}[\mathrm{F}(\mathrm{p})]}{\mathrm{dp}}+\frac{1}{\mathrm{p}} \frac{\mathrm{d}^{2}[\mathrm{~F}(\mathrm{p})]}{\mathrm{dp}^{2}}=-\frac{\mathrm{a}_{1}}{\mathrm{p}^{5}}$

For estimating $\mathrm{a}_{1}$ we need to return to the time domain by mean of an inverse Laplace transform using the following properties :

$L^{-1}\left\{\frac{F(p)}{p}\right\}=\int_{0}^{t} f(\tau) d \tau ; L^{-1}\left\{\frac{d F(p)}{d p}\right\}=-t f(t)$ et $L-1\left\{\frac{1}{p^{n}}\right\}=\frac{t^{n-1}}{(n-1) !}$

We obtain :

$3 \int^{[3]} f(\tau) d \tau-5 \int^{[2]} \tau f(\tau) d \tau+\int_{0}^{t} \tau^{2} f(\tau) d \tau=-\frac{t^{4}}{4 !} a_{1}$ 
Where $\int^{[\mathrm{n}]} \mathrm{f}(\tau) \mathrm{d} \tau=\int_{0}^{\mathrm{t}} \int_{0}^{\tau_{1}} \cdots \int_{0}^{\tau_{\mathrm{n}-1}} \mathrm{f}\left(\tau_{\mathrm{n}}\right) \mathrm{d} \tau_{\mathrm{n}} \cdots \mathrm{d} \tau_{1}$ is the $\mathrm{n}^{\text {th }}$ anti-derivative of $\mathrm{f}(\mathrm{t})$

To make it easier to compute the successive integrations one should use the Cauchy theorem :

$\int^{[n]} f(\tau) d \tau=\int_{0}^{t} \frac{(t-\tau)^{n-1}}{(n-1) !} f(\tau) d \tau$

Finally the algebraic estimator of $\mathrm{a}_{1}$ is written as :

$\mathrm{a}_{1}=-\frac{24}{\mathrm{t}^{4}} \int_{0}^{\mathrm{t}}\left[\frac{3}{2}(\mathrm{t}-\tau)^{2}-5 \tau(\mathrm{t}-\tau)+\tau^{2}\right] \mathrm{f}(\tau) \mathrm{d} \tau=\int_{0}^{\mathrm{t}} \mathrm{P}_{1}(\tau) \mathrm{f}(\tau) \mathrm{d} \tau$

To obtain an estimate of the first derivative of a signal at any point, the calculation of $a_{1}$ must be performed over a sliding window integration of duration $T$. In order to do this, $t$ should be substituted with $\mathrm{T}$ in expression (5).

\section{3) Comments}

- Although the theoretical demonstration seems complex, the use of the algebraic derivative estimator is very simple because it is based on the calculus of an integral which can be carried out by a linear filter.

- At the cost of an extra calculation, this method can easily be generalized to an initial polynomial of any degree $n$.

- The great advantage of this method is the estimation of the derivative in an integral manner and that the estimation of a specific coefficient does not require that of others.

- The coefficient $\mathrm{a}_{0}$ provides access to the denoised signal. Using the same approach than previously we get:

$$
\mathrm{a}_{0}=\frac{3}{\mathrm{t}^{3}} \int_{0}^{\mathrm{t}}\left[3(\mathrm{t}-\tau)^{2}-6 \tau(\mathrm{t}-\tau)+\tau^{2}\right] \mathrm{f}(\tau) \mathrm{d} \tau
$$

- Similarly, the second derivative can be estimated by :

$$
\mathrm{a}_{2}=\frac{60}{\mathrm{t}^{5}} \int_{0}^{\mathrm{t}}\left[(\mathrm{t}-\tau)^{2}-4 \tau(\mathrm{t}-\tau)+\tau^{2}\right] \mathrm{f}(\tau) \mathrm{d} \tau
$$

\section{IV - Application to typical currents}

\section{1) Block diagram of the discrete algebraic differentiator}

For the sampled current $I_{k}$, the integration window has a width $T=\mathrm{MT}_{\mathrm{s}}$

Where $\mathrm{T}_{\mathrm{s}}=\frac{1}{\mathrm{f}_{\mathrm{s}}}$ is the sampling period and $\mathrm{M}$ a chosen integer

The discrete version of the polynomial $\mathrm{P}_{1}(\tau)$ from eq. (5) becomes :

$\mathrm{P}_{1}(\mathrm{~m})=-\frac{24}{\mathrm{M}^{4}} \mathrm{f}_{\mathrm{s}}^{2}\left[\frac{3}{2}(\mathrm{M}-\mathrm{m})^{2}-5 \mathrm{~m}(\mathrm{M}-\mathrm{m})+\mathrm{m}^{2}\right]$ for $0 \leq \mathrm{m} \leq \mathrm{M}$

The discrete computation of expression (5) can be represented by the diagram in Figure 10. 


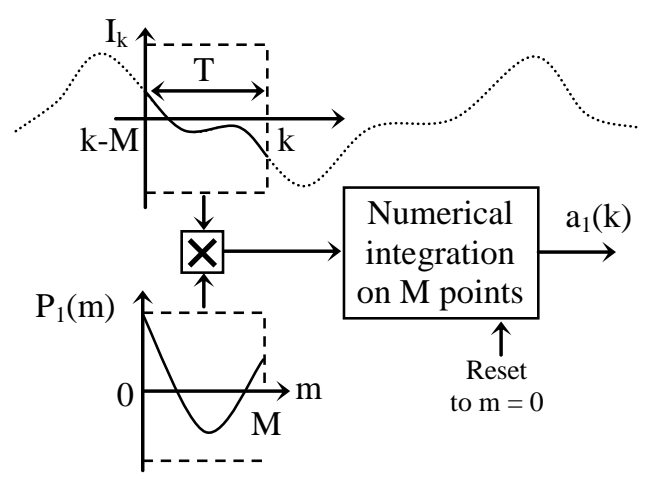

Figure 10. Graphical representation of the discrete algebraic derivative

For a better accuracy, the numerical integration must be performed by the trapezoidal method. It is imperative to reset the integrator at each displacement of the observation window.

\section{2) Choice of the integration duration}

The finite differences method uses a geometric approach to estimate the derivative of a signal. In practice, it is limited to $1^{\text {st }}, 2^{\text {nd }}$ or $4^{\text {th }}$ order and needs a low-pass prefiltering.

The algebraic derivative estimation corresponds to a convolution between the current signal with a particular polynomial. It allows using a number more important of points.

The algebraic estimator behaves as a high gain band-pass filter whose the upper cut-off frequency is inversely proportional to the duration MTs. The integration time must be adapted to the discontinuities duration that is desired to highlight. To ensure a precise temporal location of discontinuities, it is necessary to use a short window.

In our tests, the integration window is set at about 3 times the arc restrike duration ( $\mathrm{T}$ between 10 and $300 \mu \mathrm{s})$. In AC mode, an integration longer than $1 \mathrm{~ms}$ shows the discontinuities and also the fundamental component $(50 \mathrm{~Hz})$ of the current.

\section{3) Detecting a discontinuity in DC systems - Comparison}

We use the current signal measured in test 1 and its $4 \mathrm{kHz}$-filtered version in order to compare the performance of the algebraic differentiator (AD) with those of a finite difference differentiator (FD). As shown in Figure 5, this filter removes a large part of the measurement and quantification noise.

For the FD we use an order 1 difference of the form : $\frac{I_{k}-I_{k-1}}{T_{s}}$

The modulus of the derivative estimated by FD is shown in Figure 11. Here the detection of a discontinuity of the current (at time $t=50 \mathrm{~ms}$ ) seems very difficult to achieve reliably.

Things improve significantly by operating on the filtered signal (Figure 12). In this case, the ratio $\xi$ between the peak of the derivative and the noise level (in the absence of an arc) is about 4 . Note that the filter greatly reduces and enlarges the derivation peak. 


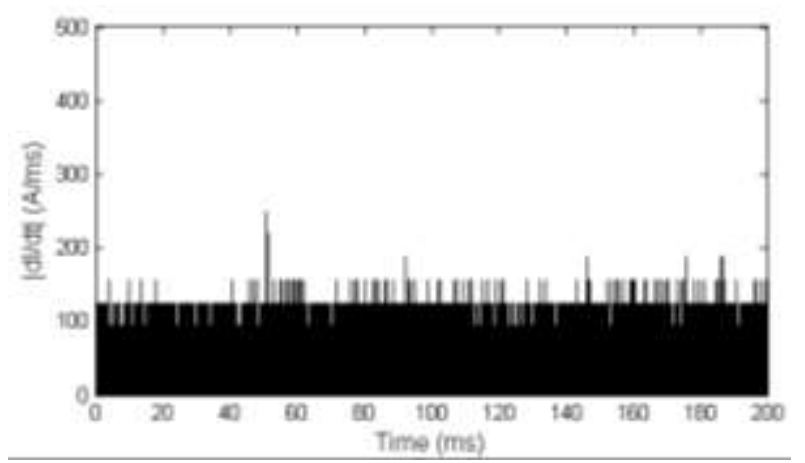

Figure 11. FD applied to the unfiltered DC current

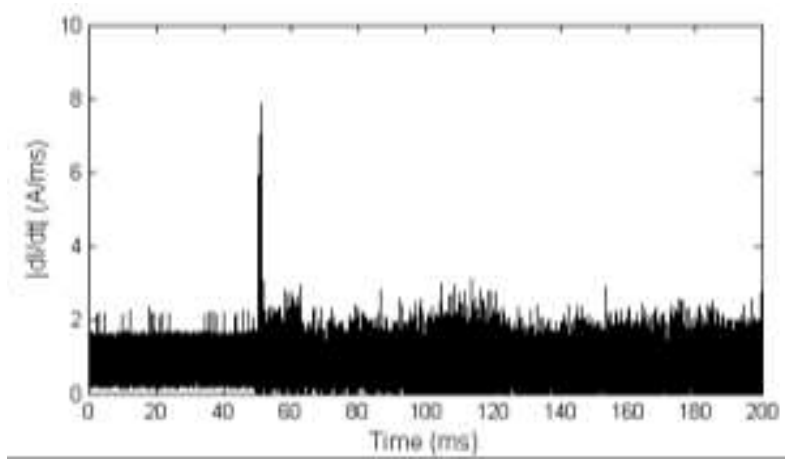

Figure 12. FD applied to the filtered DC current

The results of the estimation performed by the algebraic differentiator on the same signals are represented in Figures 13 and 14.

The integration window is 3 times the ignition time of the arc, that is $\mathrm{T}=200$ microseconds. This ensures sufficient time accuracy of the times of arc detection.

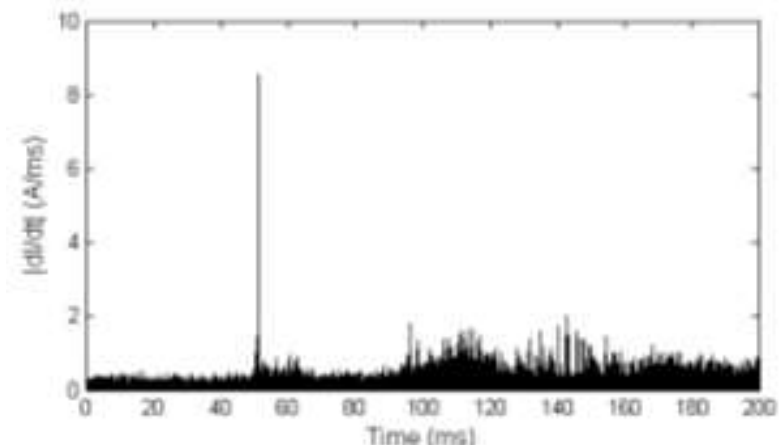

Figure 13. AD applied to the unfiltered DC current

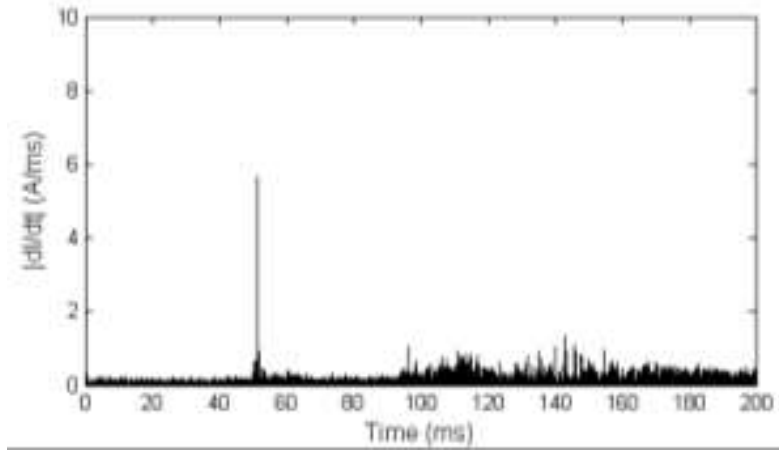

Figure 14. AD applied to the filtered DC current 
One can note a $\xi$ ratio of 17 with respect to the initial signal and 24 with respect to the filtered signal.

The level and the peak width of the derivative are only weakly altered by the filter.

Compared to the finite difference method, the algebraic approach dramatically improves the dynamic of the useful derivative signal. Moreover the peak of the derivative can be localized with greater accuracy.

\section{3) Application to AC currents}

The algebraic differentiator was applied to four types of AC current with an integration window set to $\mathrm{T}=50$ microseconds. This value is again about 3 times the rise time of the current in an arc restrike phase.

The plots of $\left|\frac{\mathrm{dI}}{\mathrm{dt}}\right|$ are shown in Figures 15 to 18.

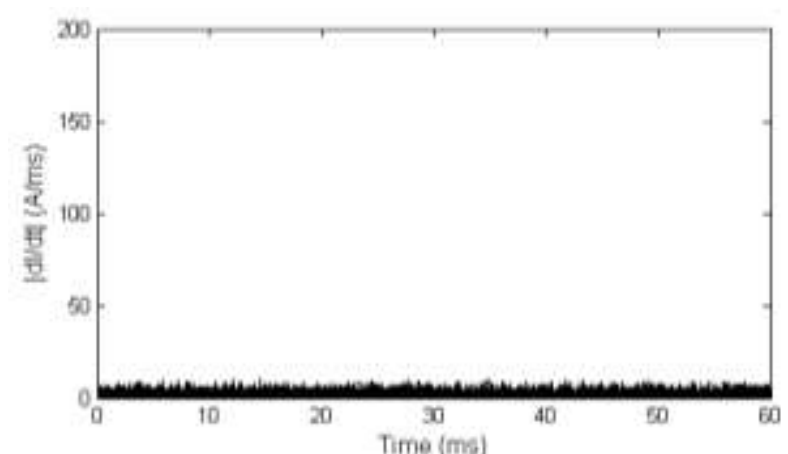

Figure 15. Modulus of the derivative of the current in a resistive load without series arc

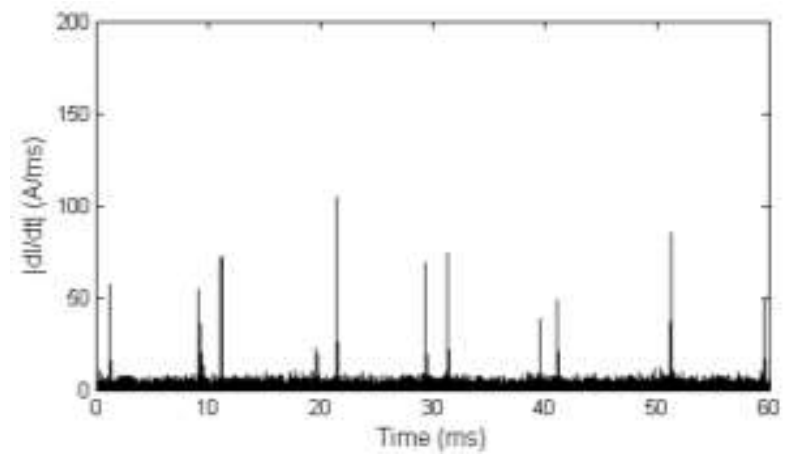

Figure 16. Modulus of the derivative of the current in a resistive load with a series arc

The restrike phases of the arc are properly highlighted. With a $\xi$ factor greater than 10 in most cases, the contrast with the base line is significant.

Note : the compliance of the values of the derivative provided by the estimator (60 to $120 \mathrm{kA} / \mathrm{s}$ ) with that of $110 \mathrm{kA} / \mathrm{s}$ mentioned in paragraph II.4. 


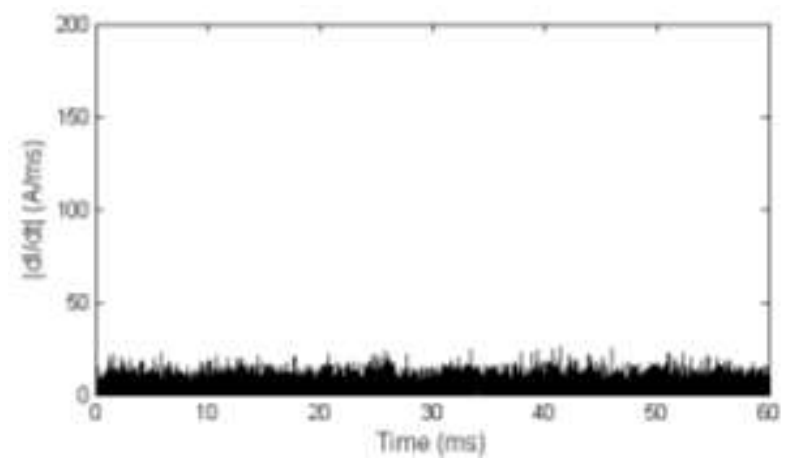

Figure 17. Modulus of the derivative of the current in a universal motor without series arc

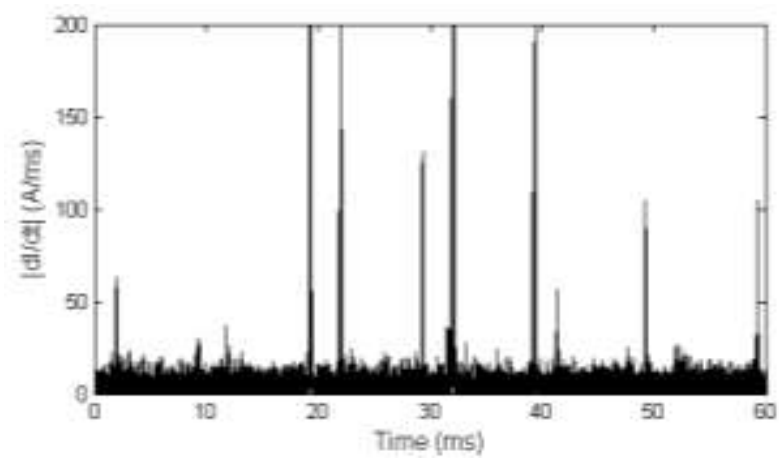

Figure 18. Modulus of the derivative of the current in a universal motor with a series arc

In the presence of the motor and despite a doubling of the level of the baseline, the re-strike phases remain perfectly visible.

\section{V - Estimation filter for the algebraic derivative}

As suggested in Figure 10, the discretized version of the algebraic differentiator may be synthesized in the form of an FIR filter with $M+1$ coefficients $h_{m}$. This filter obeys the general difference equation :

$$
\mathrm{a}_{1}(\mathrm{k})=\sum_{\mathrm{m}=0}^{\mathrm{M}} \mathrm{h}_{\mathrm{m}} \mathrm{I}_{\mathrm{k}-\mathrm{m}}
$$

Where the coefficients $h_{m}$ correspond to the values $P_{1}(M-m)$

The only difference is that the integration done by the filter becomes a simple summation.

In order to compute the trapezoidal integration described in Figure 19, we have to slightly modify the impulse response of the filter.

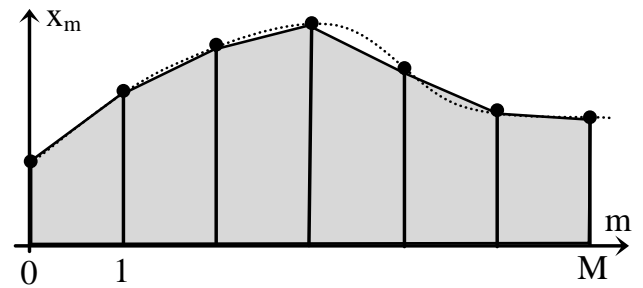

Figure 19. Numerical integration with the trapeze method

The trapezoidal integration of the signal $\mathrm{x}_{\mathrm{m}}$ for $0 \leq \mathrm{m} \leq \mathrm{M}$ follows :

$$
\mathrm{T}_{\mathrm{s}}\left[\frac{\mathrm{x}_{0}+\mathrm{x}_{1}}{2}+\frac{\mathrm{x}_{1}+\mathrm{x}_{2}}{2}+\cdots+\frac{\mathrm{x}_{\mathrm{M}-1}+\mathrm{x}_{\mathrm{M}}}{2}\right]=\mathrm{T}_{\mathrm{s}}\left[\frac{\mathrm{x}_{0}}{2}+\sum_{\mathrm{m}=1}^{\mathrm{M}-1} \mathrm{x}_{\mathrm{m}}+\frac{\mathrm{x}_{\mathrm{M}}}{2}\right]
$$


To make the filter achieves this integration, it is sufficient to affect to the coefficients $h_{0}$ and $h_{M}$ respectively the values $\frac{\mathrm{P}_{1}(\mathrm{M})}{2}$ and $\frac{\mathrm{P}_{1}(0)}{2}$.

By deferring the scale factor $G=-\frac{24}{M^{4}} f_{s}$ to the end of the chain, we arrive at the filter structure depicted in Figure 20.

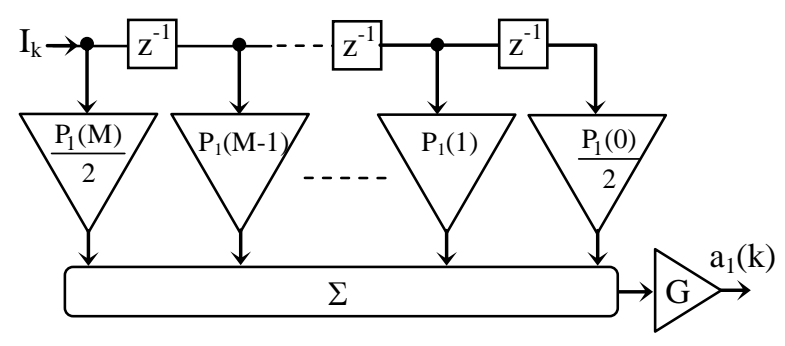

Figure 20. Structure of the estimation filter for the first derivative

\section{VI - Proposal of an AC series arcs detector}

\section{1) Qualitative tests on a multisignal sequence}

We tested the algebraic derivative filter on a sequence of $1.3 \mathrm{~s}$ formed by the succession of $\mathrm{AC}$ currents measured on various charges in the absence and in the presence of series arcs (test 4). This sequence, shown in Figure 21, comprises 10 areas corresponding to the specifications given in Table 2. Each area contains 13 half-period.

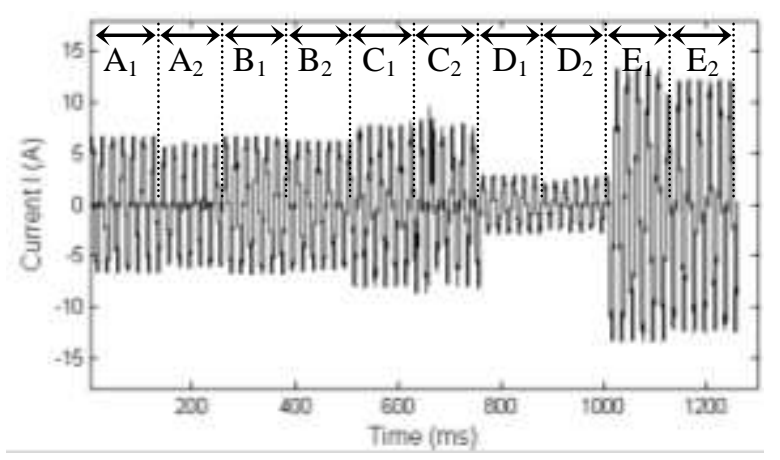

Figure 21. Sequence of the test signals

\begin{tabular}{|c|c|c|}
\hline Zones & Charge Type & Power $(\mathbf{W})$ \\
\hline $\mathrm{A}_{\mathrm{j}}$ & Dimmer & 900 \\
\hline $\mathrm{B}_{\mathrm{j}}$ & $\mathrm{R}=48 \Omega$ & 1000 \\
\hline $\mathrm{C}_{\mathrm{j}}$ & Vacuum cleaner & 1250 \\
\hline $\mathrm{D}_{\mathrm{j}}$ & Drill & 750 \\
\hline $\mathrm{E}_{\mathrm{j}}$ & $\mathrm{R}=24 \Omega$ & 2000 \\
\hline \multicolumn{2}{|c|}{$\mathrm{j}=1:$ without series arc $; \mathrm{j}=2:$ with series arc } \\
\hline
\end{tabular}

Table 2. Specifications of the test 4

Due to the sinusoidal nature of the current, the derivative signal has a $50 \mathrm{~Hz}$ component whose amplitude equals $2 \pi$ times that of the current. To overcome this unnecessary component, the fundamental frequency of the current is removed before applying the differentiator.

This preprocessing is carried out using a selective notch filter whose transfer function is $\mathrm{H}_{\mathrm{N}}(\mathrm{z})$ (Figure 22). 


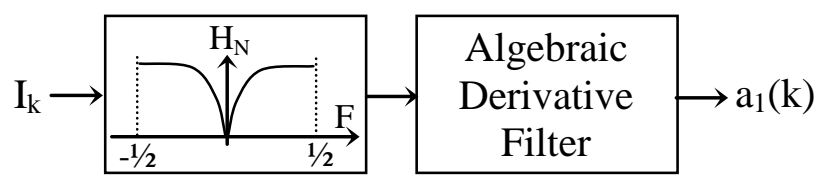

Figure 22. Notch Filter before derivation

$\mathrm{H}_{\mathrm{N}}(\mathrm{z})=\frac{1-2 \mathrm{z}^{-1}+\mathrm{z}^{-2}}{1-2(1-\mathrm{e}) \mathrm{z}^{-1}+(1-\mathrm{e})^{2} \mathrm{z}^{-2}}=\left[\frac{1-\mathrm{z}^{-1}}{1-(1-\mathrm{e}) \mathrm{z}^{-1}}\right]^{2}$ where $\mathrm{e}=0.01$

The bandwidth rejected around the zero frequency by this filter is given by $\Delta f_{-3 d B}=\frac{e}{\pi} f_{s}$

Given the sampling rate of $1 \mathrm{MHz}$, we used a low factor e.

The modulus of the response $\mathrm{a}_{1}(\mathrm{k})$ shown in Figure 23, shows that the level of the base line depends on the current amplitude and the nature of the load; reactive loads being the most polluting. The contrast factor is on average to 8 .

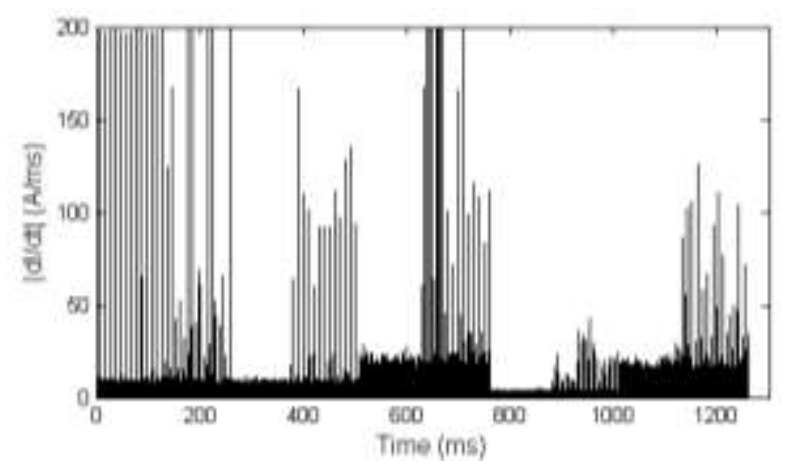

Figure 23. Response of the algebraic derivative filter

\section{2) Baseline extraction}

In order to normalize the response of the estimator, it is possible to divide it by the average current amplitude. This simple strategy is not appropriate here because it ignores the noise generated by the load and its accuracy becomes very poor in case of a low current value. The baseline we adopt corresponds to the noise level of signal $\mathrm{a}_{1}(\mathrm{k})$. To extract this level, we initially trimmed signal $\mathrm{a}_{1}(\mathrm{k})$ and then applied an amplitude detector (Figure 24).

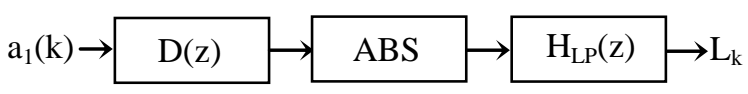

Figure 24. Baseline extraction module

The baseline extraction is automatic and does not require the a priori knowledge of its level.

The trimming filter $\mathrm{D}(\mathrm{z})$ used here is a simple differentiator whose transfer function is given by :

$\mathrm{D}(\mathrm{z})=\left(1-2 \mathrm{z}^{-1}+\mathrm{z}^{-2}\right)^{2}$

A nonlinear method like an outlier filter is probably more efficient but we have not checked this.

The output of the trimming filter is shown in Figure 25. Apart from some residual peaks, the baseline is well extracted. 


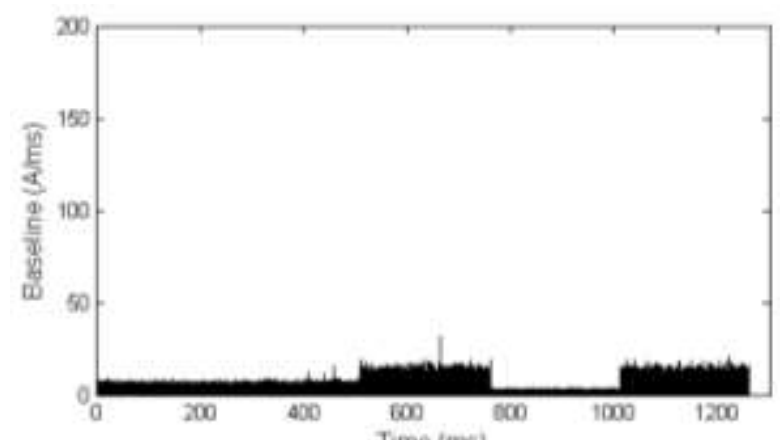

Figure 25. Baseline extracted by the trimming filter

The ABS unit delivers the absolute value of the clipped signal.

The final smoothing filter takes a transfer function $\mathrm{H}_{\mathrm{LP}}(\mathrm{z})$ complementary to $\mathrm{H}_{\mathrm{N}}(\mathrm{z})$.

$\mathrm{H}_{\mathrm{LP}}(\mathrm{z})=\mathrm{e}^{2} \frac{1+2 \mathrm{z}^{-1}+\mathrm{z}^{-2}}{1-2(1-\mathrm{e}) \mathrm{z}^{-1}+(1-\mathrm{e})^{2} \mathrm{z}^{-2}}=\mathrm{e}^{2}\left[\frac{1+\mathrm{z}^{-1}}{1-(1-\mathrm{e}) \mathrm{z}^{-1}}\right]^{2}$ with $\mathrm{e}=0.01$

To avoid the use of a coefficient e too close to 0 , it is possible to perform decimation before smoothing the signal.

The level $\mathrm{L}_{\mathrm{k}}$ delivered by the baseline extraction module is shown in Figure 26.

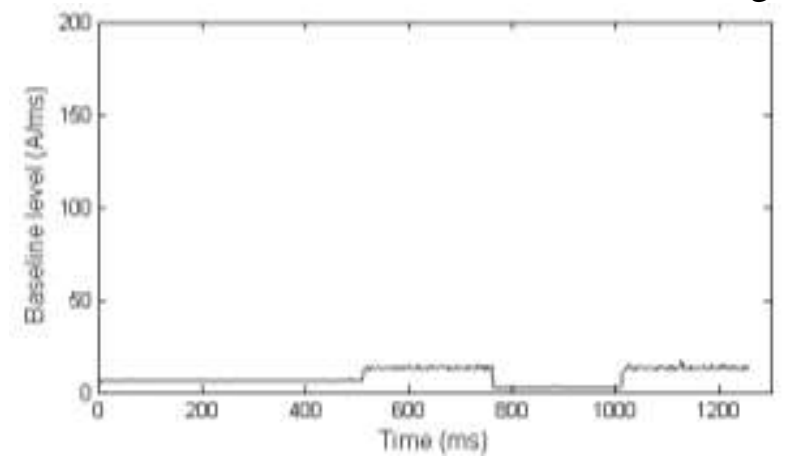

Figure 26 Output of the baseline extraction module

\section{3) Arc-fault detection results}

At each instant $\mathrm{k}$, the $\mathrm{AC}$ arc detector (Figure 27) performs the comparison of the samples $\mathrm{a}_{1}(\mathrm{k}$ ) with the level of the baseline. The output indicator "arc warning" is activated when a peak exceeds the threshold K. $\mathrm{L}_{\mathrm{k}}$

$\mathrm{K}$ is a fixed factor which avoids false detection associated with the residual noise level present in $\mathrm{L}_{\mathrm{k}}$. Given the dynamic of the algebraic derivation, a value of $\mathrm{K}$ between 2 and 5 ensures a reliable detection.

A value of $\mathrm{K}$ higher to 2 allows avoiding the false detections due to residual fluctuations of the baseline level. With a value less than 5, the detection flag is enabled in each sample of the discontinuity whatever the load used. For values higher to 5, the temporal density of the detection flag decreases.

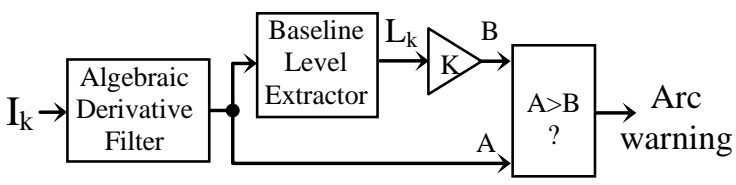

Figure 27. Schéma du détecteur d'arc AC 
Figure 28 shows the response of the detector to the multi-signal sequence with a $\mathrm{K}$ factor fixed to 3 . Except for the case of the dimmer, the half periods which have an arc fault (13 for each load) are detected without ambiguity.

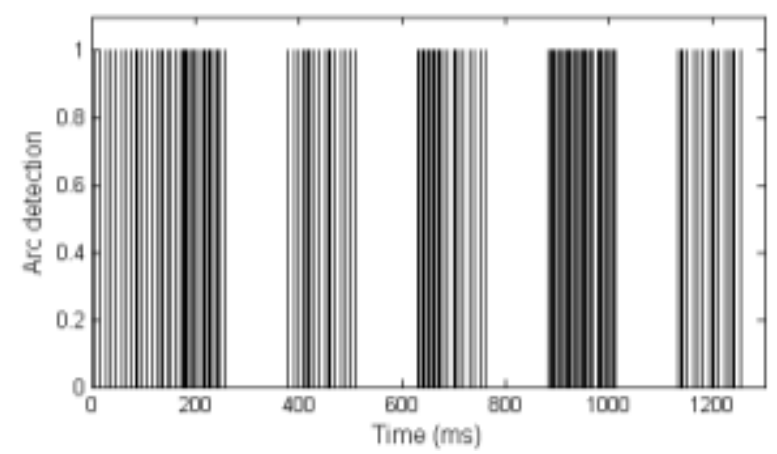

Figure 28. Output of the AC arc detector

This method can quickly detect $(50 \mu \mathrm{s})$ the presence of $\mathrm{AC}$ arcs in a circuit including resistive or reactive loads such as a motor.

But the downside is that false detections appear at each discontinuity of the current in the case of a dimmer load. In such situations, the presence of an arc is shown by an increase in the density of the peaks in the derivative.

\section{VI - Conclusion}

The derivative of the line current can be used for detecting arcs in AC systems that do not include switched mode loads (dimmer, SMPS, ...). In the opposite case or for DC systems, the detection must be confirmed by an additional indicator such as the presence of RF interferences generated by an arc.

We chose an algebraic estimate of the first derivative in order to :

- Ensure adequate measurement noise and disturbance immunity;

- Limit the number of adjustable parameters which is reduced to the selection of the length of the sliding observation window;

- Simplify its hardware implementation.

The estimator takes the form of a running integration of the product of the instantaneous current with a particular polynomial. Integration duration of 50 microseconds for AC systems and 200 microseconds for DC systems is sufficient to highlight peaks generated by arcs in the derivative.

The discrete version can be synthesized quickly and easily with an FIR filter slightly modified to ensure a trapezoidal integration.

The tests on actual current measurements result in a contrast ratio between the peaks and the derivative baseline greater than 8 . The presence of an arc becomes highly legible, thus facilitating the choice of the decision threshold.

The detection is performed by mean of a real-time comparison between the level of the baseline and the output of the derivative estimation filter.

The arc detector implementation in an FPGA target is under development. The algebraic derivation is synthesized with a transverse structure of variable length.

The chaotic nature of an arc generates the discontinuities on the current waveform and also on its frequency and statistic characteristics. The algebraic derivative may be used to detect the breaks on these attributes.

\section{Acknowledgment}

The authors thank Cedric Join for his advices. 


\section{References}

[1] FEMA 2008, Topical Fire report series: Residential building electrical Fires. United States Fire Administration, Volume 8, issue 2 march 2008.

[2] Z.M Radojevic, V.V. Terzija, M.B. Djurié." Spectral domain arcing fault recognition and fault distance calculation in transmission systems. Electrical Power Systems Research 37 (1996) 105-113.

[3] MF. Walz and al, "An Analysis of arc Fault Ignition and Mitigation Techniques," Federal aviation administration. $\mathrm{Nj} 08405$.

[4] X. Zhou, J.J. Shea, K.L. Parker, and T.J. Miller,"Arc fault circuit interrupter and series arc fault detection method using plural high frequency bands" US 7558033 ed: Google Patents, 2009

[5] T. E Potter, M. Lavado, Arc Fault Circuit Interruption-Requirements for Aircraft Applications , Texas Instruments, http://www.sensata.com/download/ arcfault-requirements-aircraft.pdf.

[6] J. Lezama, P. Schweitzer, S. Weber, E.Tisserand, P. Joyeux and M. Rabla, Frequency Analysis to Arcing Detection and Prototyping FPGA Approach, Proceedings of the 59th IEEE Holm Conference on, 2013

[7] K.Y Lien and al, "Energy variance criterion and threshold tuning scheme for high impedance fault detection", IEEE Transaction on Power Delivery, Vol.14. Iss 3.

[8] M. Rabla, P. Schweitzer, E. Tisserand, Method to design arc fault detection algorithm using FPGA, Proceedings of the 57th IEEE Holm Conference on, 2013

[9] X. Yao and al, "DC Arc Fault: Characteristic Study and Fault Recognition"1 ${ }^{\text {st }}$ International Conference on Electric Power Equipment. 2011.

[10] P. Muller and al,"Characteristics of series and parallel low current arc faults in the time and frequency domain" $56^{\text {th }}$ IEEE Holm Conference on Electrical contacts, Oct 2010.

[11] Ye. Xiao-Mei, L. Xiao-he, "The harmonic detection based on wavelet transform and FFT for electric arc,"ICWAPR 2009 International Conference on Wavelet Analysis and Pattern Recognition July 2009.

[12] W. J. Li, Y. C. Li, "Arc fault detection based on wavelet packet », in Machine Learning and Cybernetics, 2005. Proceedings of 2005 International Conference on, 2005, vol. 3, p. 1783-1788.

[13] C.J. Buchenauer, "Modeling of experiments for measuring dynamic arc impedance" The $31^{\text {st }}$ IEEE International Conference on Plasma Science (2004)

[14] J.B. Beck, D.C Nemir, "Arc fault detection through model reference estimation" Power Systems Conference (2006)

[15]L. Kumpulainen, and al, "Preemptive Arc fault Detection Techniques in Switchgear and Controlgear" IEEE Transactions on Industry Applications (2013) Vol 49, No4.

[16] P.H. Schavemaker, L. Van der Sluis, "An Improved Mayr-Type Arc Model Based on Current-Zero Measurements", IEEE Transactions on Power Delivery (2000) Vol 15, No 2.

[17] J.L. Guardado and al, "An improved arc model before current zero based on the combined Mayr and Cassie arc models”. IEEE Transactions on Power Delivery (2005) Vol 20, No 1.

[18] Fliess, M. and Sira-Ramırez, H., An algebraic framework for linear identification, ESAIM Control Optim. Calc. Variat., vol. 9, 2008, pp 151-168.

[19] C. Join and S. Tabbone. Robust curvature extrema detection based on new numerical derivation. In Advanced Concepts for Intelligent Vision Systems, ACIVS 2008, Juan-les-Pins France, 2008.

[20] M. Mboup, C. Join, and M. Fliess. Numerical differentiation with annihilators in noisy environment, Numerical Algorithms, 50, 4 (2009) 439-467.

[21] J. Andrea, P. Schweitzer, E. Tisserand, P. Roth, et S. Weber, Calibrated AC and DC Arcing Fault Generator, 2010 Proceedings of the 56th IEEE Holm Conference on, 2010, p. 1-6

[22] J.J. Shea, Conditions for Series Arcing Phenomena in PVC Wiring, IEEE Transactions on Components and Packaging Technologies vol. 30, no. 2, June 2007.

[23] J.J. Shea, Identifying Causes For Certain Types Of Electrically Initiated Fires in Residential Circuits. Published online 19 July 2010 in Wiley Online Library

[24] Underwriters Laboratories (UL), UL Standard for Safety for Arc-Fault Circuit- Interrupter, UL 1699b.

[25] Sonia Rezk, Cedric Join, and Sadok El Asmi, An algebraic derivative based method for R wave detection, 19th European Signal Processing Conference, EUSIPCO, 2011

[26]D. Benitz, P. Gaydecki, A. Zaidi, and A. Fitzpatick. A new QRS detection algorithm based on the hilbert transform. Computers in Cardialogy, 27:379-382, 2000.

[27] M. Fliess, C. Join, and M. Mboup. Algebraic change-point detection. Applicable Algebra in Engineering, Communication and Computing, 22(2):131-143, 2010.

[28] A. Navarro, Juan Diego Sanchez-Torres, O. Begovich, G. Besançon and Julian Alberto Patino-Murillo, An Algebraic Observer for Leak Detection and Isolation in Plastic Pipelines, , 2013 European Control Conference (ECC), 2013

[29] Giuseppe Fedele, Francesco Chiaravalloti, and Cedric Join, An algebraic derivative based approach for zero crossings estimation, , 17th European Signal Processing Conference, EUSIPCO 2009 (2009)" 